Antoni P. Tomsia ${ }^{\mathrm{a}}$, Eduardo Saiz ${ }^{\mathrm{a}}$, Sonia Lopez-Esteban ${ }^{\mathrm{b}}$, Mehdi Benhassine ${ }^{\mathrm{c}}$, Joel de Coninck ${ }^{\mathrm{c}}$, Nicole Rauch ${ }^{\mathrm{d}}$, Manfred Ruehle ${ }^{\mathrm{d}}$

${ }^{\mathrm{a}}$ Materials Sciences Division, Lawrence Berkeley National Laboratory, Berkeley, USA

${ }^{b}$ Instituto de Ciencia de Materiales de Madrid, CSIC, Spain

${ }^{\mathrm{c}}$ Centre for Research in Molecular Modelling, University of Mons-Hainaut, Mons, Belgium

${ }^{\mathrm{d}}$ Max Planck Institute für Metallforschung, Stuttgart, Germany

\title{
Wetting of metals and glasses on Mo
}

The wetting of low melting point metals and $\mathrm{Si}-\mathrm{Ca}-\mathrm{Al}-\mathrm{Ti}-\mathrm{O}$ glasses on molybdenum has been investigated. The selected metals $(\mathrm{Au}, \mathrm{Cu}, \mathrm{Ag})$ form a simple eutectic with Mo. Metal spreading occurs under nonreactive conditions without interdiffusion or ridge formation. The metals exhibit low (non-zero) contact angles on Mo but this requires temperatures higher than $1100{ }^{\circ} \mathrm{C}$ in reducing atmospheres in order to eliminate a layer of adsorbed impurities on the molybdenum surface. By controlling the oxygen activity in the furnace, glass spreading can take place under reactive or nonreactive conditions. We have found that in the glass/Mo system the contact angle does not decrease under reactive conditions. In all cases, adsorption from the liquid seems to accelerate the diffusivity on the free molybdenum surface.

Keywords: Wetting; Interface; Glasses; Liquid metals; Interfacial energies 


\section{Introduction}

The high temperature wetting of liquid metals and oxides plays an important role in many technologies. From brazing to composite fabrication, the control of wetting is critical to optimize processes and materials. Wetting is intimately related to fundamental physicochemical processes that often act at the atomic level. Wetting experiments are often the only probes available to measure fundamental quantities directly linked to atomic structure and bonding at interfaces, such as the interfacial energies or the thermodynamic work of adhesion between two phases. In this respect, high-temperature wetting is strongly affected by factors such as adsorption, interdiffusion, chemical reactions or triple line ridging whose role in the spreading of metals and glasses is still not fully understood and subject of controversy [1-13].

In this work we compare the nonreactive wetting of low melting point metals and oxides on Mo. These systems have important technological applications (e.g., in glass sealing or in the moly-manganese metallization process where control of the atmosphere is critical) [14-17] due to the resistance of Mo to corrosion and its refractory nature. They are also excellent model systems. Due to the high melting point of $\operatorname{Mo}\left(2615^{\circ} \mathrm{C}\right)$, the interfacial diffusion and transport rates are slow compared with the experimental times and the substrate can be considered effectively inert. The studies with glasses have an additional advantage: By controlling the oxygen partial pressure, the interface can be changed from nonreactive to reactive. Above some critical oxygen activity, there is no chemical reaction or interdiffusion between the glass and the metal, but below it, they will react to form molybdenum silicides. For most technological processes, from glass sealing to soldering or brazing, spreading is accompanied by chemical 
reactions. Because the glass/metal reactivity can be controlled by such a simple method, this system provides a unique opportunity to ascertain how chemical reactions affect wetting.

\section{Experimental}

The contact angle of liquid fcc metals $(\mathrm{Ag}, \mathrm{Au}, \mathrm{Cu})^{1}$ and silicate glasses (Table 1) on polycrystalline ${ }^{2}$ molybdenum substrates was analyzed using a side-loading furnace (series 15 , CENTORR Vacuum Industries, Nashua, NH, USA) with a tungsten heating element. The experiments were performed under controlled oxygen activity by flowing $\mathrm{Ar} / \mathrm{H}_{2}$ mixtures at $\sim 2 \cdot 10^{-5} \mathrm{~m}^{3} \mathrm{~s}^{-1}\left(\mathrm{p}(\mathrm{Ar}) \approx 10^{5} \mathrm{~Pa}\right)$. The oxygen content of the gas leaving the furnace was monitored using a $\mathrm{ZrO}_{2}$ sensor (Centorr, model 2D, USA). The glasses were prepared following . a conventional procedure described in detail elsewhere [18]. The substrates were either mechanically or electrolitically polished. For the mechanical polishing, the Mo surfaces were ground with $1200 \mu \mathrm{m} \mathrm{SiC} \mathrm{paper} \mathrm{and} \mathrm{afterwards} \mathrm{polished} \mathrm{on} \mathrm{an} \mathrm{automatic} \mathrm{polishing} \mathrm{machine}$ down to $1 \mu \mathrm{m}$ diamond. For the electrolitical polishing a mixture of $875 \mathrm{ml}$ of methanol (99.8\%) and $125 \mathrm{ml} \mathrm{H}_{2} \mathrm{SO}_{4}(95-97 \%)$ was used. Before the experiments, the metals, glasses and Mo substrates were cleaned with acetone and ethanol in an ultrasonic bath and dried with an air gun.

The equilibrium contact angle was measured using either a drop-transfer setup [2] or the sessile drop method [19]. For the drop transfer tests, a small piece of metal or glass $(\sim 0.1-0.2 \mathrm{~g})$ was placed on a nonreactive substrate where the liquids exhibit an obtuse contact angle (sapphire for liquid metals and boron nitride for the glasses) inside the furnace, and the Mo substrate was

\footnotetext{
${ }^{1} \mathrm{Ag}, 99.9 \%$, Johnson Matthey, USA

$\mathrm{Cu}, 99.8 \%$, Aldrich, USA

Au, $99.99 \%$, Johnson Matthey, USA

$299.9 \%$ Aldrich, USA
} 
placed on a molybdenum holder situated $\sim 10-15 \mathrm{~mm}$ above it. Subsequently, the furnace was evacuated too a pressure of $\sim 6 \cdot 10^{-4} \mathrm{~Pa}$, and refilled with gas. The assembly was heated at $15-25^{\circ} \mathrm{C} / \mathrm{min}$ to the test temperature. Two types of experiments were carried out: “equilibrated" and "non-equilibrated." For “equilibrated" tests, the Mo substrate was lowered and placed in close proximity to the liquid surface $(\sim 1 \mathrm{~mm}$ or less $)$ for $1 \mathrm{~h}$. Afterwards, the substrate was lowered slowly until it just touched the drop surface and the liquid spread on it, transferring from the ceramic plate to the molybdenum. In case of the "non-equilibrated" experiments, as soon as the required temperature was reached, the Mo was put in contact with the liquid and the wetting experiment was performed. Wetting was recorded through a transparent quartz window using a CCD camera and the contact angles and drop radius were measured using a program developed in our laboratory [20]. For the sessile drop experiments a small piece of glass or metal was placed on the Mo substrate inside the furnace, and the assembly was heated to the test temperature at $25 \mathrm{~K} \mathrm{~min}^{-1}$. In order to compare the angles reached by advancing and receding drops, the starting metal piece was shaped either as a cube or as a thin flat plate.

Before and after the experiments, the Mo surfaces were analyzed using scanning electron microscopy (Hitachi, S-4300SE/N, Japan) with associated chemical analyses (Noran System Six, Thermo, USA) by energy dispersive spectroscopy (SEM-EDS), atomic force microscopy (AFM) in the constant-force mode (Hysitron Corp, USA), scanning probe microscopy (TopoMetrix, TMX 2000, USA), and Auger electron spectroscopy (AES, JEOL JAMP-7830 F). Compositions of the Mo substrates were determined by inductively coupled plasma-atomic emission spectrometry (ICP-AES), and the grain orientation by orientation imaging microscopy (OIM). 
After the experiments, the surface of the drops and cross-sections polished with $0.3 \mu \mathrm{m} \mathrm{Al}_{2} \mathrm{O}_{3}$ were analyzed using optical microscopy and SEM-EDS.

\section{Results and Discussion}

Auger analyses of the surface of the polished substrates showed only the presence of Mo, C and O. In order to get more detailed information about the polycrystalline Mo surface such as grain size and orientation, OIM measurements were performed (Table 2). The average grain size is in the range $21-43 \mu \mathrm{m}$. About $50 \%$ of all the grains have a (311) orientation with an error of $15^{\circ}$. Around $20-25 \%$ of the grains have orientations (111) and (100). Less than $3 \%$ of the grains have a (110) orientation. The substrates have a roughness (average peak to valley distance) of 70-100 nm independently of the polishing procedure but the surfaces obtained using electrolitical polishing are much smoother. However, the polishing procedure does not have a measurable effect on the final contact angles.

\section{Liquid metals}

In all the experiments with liquid metals the oxygen partial pressure was kept below $10^{-20}$ atm to avoid oxidation or oxygen adsorption on the different surfaces. The spreading of liquid metals in the drop-transfer setup usually took $\sim 20 \mathrm{~ms}[21,22]$. After that time an equilibrium contact angle is reached. In all cases a sharp triple junction was observed after cooling. Cross-sectional analysis of the drop/substrate interface after spreading did not show any sign of reaction, interdiffusion or the formation of triple line ridges that could affect the spreading kinetics and pin the liquid front $[23,24]$. This is expected since all the selected Metal-Mo systems are simple eutectics in which there is a negligible solubility of the metals in Mo and the solubility of 
Mo in the liquids is $<3 \mathrm{wt} . \%$ at the experimental temperatures. Furthermore, the experimental temperatures are at least $1300{ }^{\circ} \mathrm{C}$ below the melting point of Mo and interfacial transport is to slow for the formation of ridges that could affect spreading kinetics.

The dependence of the final contact angle of liquid metals on temperature (Fig. 1) was much stronger than what is expected from the known variation of the metal surface energies [25]. The contact angles recorded at temperatures below $1100{ }^{\circ} \mathrm{C}$ exhibit larger variability depending on the experimental conditions (advancing vs. receding, equilibrated vs. non-equilibrated). For example, at $1100{ }^{\circ} \mathrm{C}$ there is a large difference between the angles reached in the "equilibrated" and "non-equilibrated" cases. Work by different authors indicate a strong dependence of the final contact angle of low melting point metals on Mo and W with the atmosphere [3, 26-28]. In our experiments, the oxygen partial pressures were much lower than the ones required for the oxidation of molybdenum (between $10^{-16}$ and $10^{-10}$ atm at 950 and $1300^{\circ} \mathrm{C}$ respectively) [29]. However, there is a layer of excess impurities on the Mo surface (oxygen and carbon according to the Auger analysis) that can only be eliminated after firing in $\mathrm{Ar} / 5 \% \mathrm{H}_{2}$ at temperatures above $\sim 1000{ }^{\circ} \mathrm{C}$. These results are in agreement with the work from Allen that indicates that temperatures above $1000{ }^{\circ} \mathrm{C}$ are required to eliminate oxygen from the Mo surface at a total pressure of $10^{-3} \mathrm{~Pa}$ [30]. The elimination of the impurities from the polycrystalline Mo surface can take several minutes to one hour at $1100^{\circ} \mathrm{C}$ in the hydrogen-containing atmosphere, and as a consequence there is a large variability in the final contact angle recorded at this temperature depending on the experimental conditions: equilibrated vs. non-equilibrated, advancing vs. receding, etc. 
Using a quasichemical approach that estimates the interfacial energies by adding the energy of the broken bonds, an expression for the contact angle in metal/metal systems can be found [3]:

$$
\cos \theta_{0}=\frac{\gamma_{\mathrm{lv}}^{\mathrm{Mo}}}{\gamma_{\mathrm{lv}}^{\mathrm{Me}}}-\frac{\lambda}{L_{\mathrm{e}}^{\mathrm{Me}}}
$$

Where $\gamma_{\mathrm{lv}}^{\mathrm{Mo}}$ and $\gamma_{\mathrm{lv}}^{\mathrm{Me}}$ are the liquid surface tensions of Mo and the low melting point metal

respectively, $L_{\mathrm{e}}^{\mathrm{Me}}$ is the heat of evaporation of the metal and $\lambda$ is the regular solution parameter. According to Eq. 1, in the Me/Mo systems studied here $\theta_{0}=0$ (Table 3). This, however, is not what we have observed. Even the final contact angles measured under the conditions that give the cleaner molybdenum surface are larger than 0 (although small). This result points to the limitations of the quasichemical approach that, among other things, ignores mutual adsorption and entropic effects. Adsorption and segregation usually play an important role in hightemperature wetting. It is expected that atoms from metals with lower melting points (and therefore lower surface tensions) tend to adsorb on the surface of higher melting point metals [1, 12, 31-34]. Auger analysis of the free Mo surface after the experiments indicates that adsorption of liquid atoms is probably decreasing the energy of the solid-vapor interface.

\section{Glasses}

The experiments with glasses were carried out at $1200{ }^{\circ} \mathrm{C}$ and oxygen partial pressures ranging between $10^{-16}$ and $10^{-23}$ atm in order to avoid Mo oxidation. As expected, due to their larger viscosity, glass spreading was much slower. It took 10-30 minutes for the glass to reach an equilibrium contact angle. As with the metals, a sharp triple junction was observed after cooling. 
There was no indication of the existence of a precursor foot, as has been reported for other glass/metal systems [35].

The equilibrium oxygen partial pressure for the reduction of silica and the formation of $\mathrm{Mo}_{3} \mathrm{Si}$ is $10^{-19} \mathrm{~atm}$ at $1200^{\circ} \mathrm{C}$ and even lower for the other glass components [29]. This $p\left(\mathrm{O}_{2}\right)$ can be used as approximate boundary between a non-reactive wetting situation, $p\left(\mathrm{O}_{2}\right) \geq 10^{-19} \mathrm{~atm}$, and a reactive wetting case, $p\left(\mathrm{O}_{2}\right) \leq 10^{-19} \mathrm{~atm}$. This distinction was confirmed by the microstructural analysis of the glass/metal interface. A reaction phase is clearly visible in the samples formed at oxygen partial pressures below $10^{-19}-10^{-20} \mathrm{~atm}$. Most of the reaction product could be seen in the form of small discontinuous islands around the triple line (Fig. 2). EDS analysis showed that these islands are composed of Mo-Si intermetallic, most likely $\mathrm{Mo}_{3} \mathrm{Si}$ according to the phase diagram. The formation of $\mathrm{Mo}_{3} \mathrm{Si}$ at the interface between silica-containing ceramics and molybdenum under reducing conditions has been previously described [36]. The islands were tens of microns wide and less than $1 \mu \mathrm{m}$ thick and concentrated in a narrow band $(\sim 100 \mu \mathrm{m}$ wide) around the triple junction. The presence of triple line ridges can also be clearly observed in the reactive case (Fig. 3). However, they could not be detected after the experiments performed at $p\left(\mathrm{O}_{2}\right)>10^{-19}$ atm.

The final angles measured in the reactive case are similar, even slightly larger, than those from the nonreactive experiments, contradicting the conventional expectation that reactivity enhances wetting [4] (Fig. 4). The distribution of the reaction phase indicates that most of the spreading occurs prior to the reaction and the driving forces for spreading could be written in terms of the work of separation between the unreacted phases. When spreading slows down, a ridge can form either because it is nucleated by defects on the substrate surface, or because the critical stability 
range for ridge formation has been reached. When the ridge reaches a critical height of $\sim 10-20$ $\mathrm{nm}$, its speed will be so low that experimental spreading of the liquid front stops, unless it can break away from the ridge and resume motion [23, 24]. Once the spreading velocity approaches zero, there is time for the reaction product to nucleate at the triple junction where equilibration with the surrounding atmosphere occurs faster than at the center of the drop. The small difference in angles suggests that that the equilibrium interfacial energies of the nonreactive systems and those of the metastable interfaces under reactive conditions are similar. The fact that the contact angles in the reactive case are slightly larger could suggest that the liquid front is pinned due to the formation of a ridge as the driving force for spreading approaches zero. The final contact angle in the reactive system should be that of the glass on the reaction product $\mathrm{Mo}_{3} \mathrm{Si}$, but, due to the roughness of the reaction phase, it is not possible to know if this final angle is the intrinsic value for the glass on the silicide.

The contact angles are lower for glasses with $\mathrm{TiO}_{2}$. Since the addition of 3 mol.\% $\% \mathrm{TiO}_{2}$ had a negligible effect on the surface energy of the molten glass [18], the observed decrease in the equilibrium contact angle for glasses with $\mathrm{TiO}_{2}$ additions can only be explained by the preferential adsorption of $\mathrm{TiO}_{x}$ species at the solid/liquid interface. Titania additions decrease the contact angle of silicate glasses on Pt in air [37] and there is ample evidence of adsorption of Ti-species at the interface between liquid metals and solid oxides, an effect that has been attributed to their polar nature $[1,20,28]$.

\section{Work of adhesion}

Assuming that under our experimental conditions some degree of adsorption can occur (as the Auger analyses clearly suggest), the measured contact angle will be somewhere between the 
values related to the thermodynamic work of adhesion $\left(W_{\mathrm{ad}}\right)$ between equilibrated phases and the work of separation $\left(W_{\mathrm{sep}}\right)$ between pure materials. Typically oxygen is adsorbed on a metal surface at oxygen partial pressures that are $3-8$ orders of magnitude below the critical one for bulk metal oxidation [38]. The oxygen partial pressures used in the glass experiments are only one to two orders of magnitude below the ones required for the oxidation of Mo. Oxygen adsorption could be expected on the Mo surface equilibrated with that atmosphere. In the experiments with liquid metals, the $p\left(\mathrm{O}_{2}\right)$ in the furnace is at least 6 to 10 orders of magnitude lower than the one required for oxidation and it is likely that the molybdenum surface equilibrated with this atmosphere should be free of adsorbed oxygen, except for the impurity layer that can only be eliminated after firing at higher temperatures or longer times.

Experiments performed using $\mathrm{Ag}$ and $\mathrm{Ag} / \mathrm{Mo}$ liquids have resulted in very similar final contact angles and it has been suggested that in systems with small mutual solubility the works of adhesion and separation are relatively close $[21,39]$. The similar contact angles reached by the glasses in the reactive and non-reactive cases also indicate that the work of separation between the unreacted phases is similar to the thermodynamic work of adhesion between the phases in equilibrium under nonreactive conditions. The works of adhesion calculated using the contact angles under the conditions that result in the cleaner Mo surfaces are summarized in Fig. 5. For comparison, the graph also plots the measured work of adhesion for the stoichiometric interfaces between those metals and an aluminium oxide [38, 40-42]. As expected, the works of adhesion in the metal/metal systems are larger than for the oxide/metal. It is well known that in nonreactive cases, liquid metals show obtuse contact angles on ceramics [38, 40-42]. On the other hand, molten oxides tend to exhibit low contact angles on the metals $[3,34,43]$, a fact that is usually attributed to their low surface tension [3]. 


\section{Surface diffusion}

After removing the glass drops formed under reactive conditions, grain boundary grooves were clearly visible at the glass/metal interface and on the free Mo surface. The groove shape is consistent with grooving controlled by diffusion and the groove widths at the glass/Mo interface or at the free Mo surface close to the triple line are very similar, $\sim 0.8-1 \mu \mathrm{m}$ after 2 hours at $1200{ }^{\circ} \mathrm{C}$. However, the width of the groove clearly decreased as we moved away from the triple junction towards the edge of the Mo substrate. Similar groove sizes were observed for glasses with or without $\mathrm{TiO}_{2}$. These results show that at very low oxygen activities, the presence of glass enhances mass transport at the metal surface and at the metal/glass interface. The grooves are wider at the metal/ceramic interface and on the metal surface close to the liquid front. Such behavior suggests that enhanced transport is due to adsorption of glass species at very low oxygen activities (or in atmospheres with higher $\mathrm{H}_{2}$ content). Auger analyses have shown the presence of $\mathrm{Ca}$ peak at the glass/metal interface and on the free Mo surface. Since groove growth is controlled by interfacial diffusion (the solubility of Mo in the glass is negligible), the corresponding interfacial diffusivities can be estimated using measured groove widths. According to Mullins, the groove width ( $w$ ) should evolve with time as [44]:

$$
w=4.6\left(\frac{B_{i} t}{2}\right)^{1 / 4}
$$

where $B_{i}$ is the corresponding interfacial transport coefficient:

$$
B_{i}=\frac{\omega D_{i} \gamma_{i} \Omega}{k T}
$$


with $\omega D_{i}$ being the width-diffusivity product for the specific interface; $\Omega$, the atomic volume; and $k$, Boltzmann's constant. For the observed groove widths ( $\sim 1 \mu \mathrm{m}$ wide after 2 hours), the calculated $B_{i}$ for the solid-liquid and solid-vapor interfaces are $\sim 6.2 \cdot 10^{-31} \mathrm{~m}^{4} \mathrm{~s}^{-1}$. By choosing $\gamma_{\mathrm{Mo}} \sim 2.5 \mathrm{~J} \mathrm{~mol}^{-1}[25]$ and $\Omega \sim 1.6 \cdot 10^{-29} \mathrm{~m}^{3}$, the corresponding diffusivities, $\omega D_{i}$, are of the order of $10^{-22} \mathrm{~m}^{3} / \mathrm{s}$. In parallel, analysis of the evolution of grain boundary grooves in the $\mathrm{Ag} / \mathrm{Mo}$ systems was performed by recording the width of grain boundary grooves on Mo substrates placed in close proximity $(<1 \mathrm{~mm}$ ) to the top silver drop with the drop transfer setup (Fig 6).

The activation energy for the surface diffusivity $\left(\sim 230 \mathrm{~kJ} \mathrm{~mol}^{-1}\right)$ is of the order or slightly lower than those reported for pure Mo (Fig. 7). Correspondingly, the diffusivities are similar or slightly larger. In the absence of silver or in experiments performed with glass under nonreactive conditions, the grain boundaries of Mo are too narrow to determine the surface diffusivity. Therefore, it seems that the surface diffusivities measured here correspond to Mo surfaces with some degree of adsorption (as confirmed by the Auger analysis). These values are larger than expected from reported transport coefficients for pure Mo [45].

\section{Conclusions}

Molybdenum substrates have a layer of adsorbed impurities (mostly oxygen and carbon) that can only be eliminated after firing at high temperature. As a result, the nonreactive contact angle of liquid metals on Mo can exhibit a large variability depending on the experimental conditions (time, temperature and atmosphere). Under conditions that result in "clean" Mo surfaces the metals exhibit a very low (but non-zero) contact angle. Silicate glasses also exhibit a low, finite contact angles. The final angles do not depend strongly on the oxygen activity of the system, despite the fact that at higher oxygen activities $\left(p\left(\mathrm{O}_{2}\right)>10^{-19} \mathrm{~atm}\right)$ nonreactive spreading takes 
place while at lower oxygen partial pressures, the glass and the metal should react to form an intermetallic phase and the substrate exhibit at enhanced interfacial diffusion. In both cases, metals and glasses, adsorption from the liquid enhances surface diffusion on the Mo surface.

This work was supported by the Director, Office of Science, Office of Basic Energy Sciences, Materials Sciences and Engineering Division, of the U.S. Department of Energy under Contract No. DE-AC02-05CH11231. S. Lopez-Esteban has been supported by the Spanish Ministry of Education and Science under Ramon y Cajal Program. M. Benhassine thanks FRIA (Belgium) for its support. We gratefully thank Dr. Wilfried Sigle for fruitful discussions.

\section{References}

[1] E. Saiz, R. M. Cannon, A. P. Tomsia: Acta Mater. 48 (2000) 4449.

[2] E. Saiz, A. P. Tomsia: Curr. Opin. Solid. St. Mat. Sc. 9 (2005) 167.

[3] N. Eustathopoulos, M. G. Nicholas , B. Drevet: Wettability at High Temperatures, Pergamon, Amsterdam (1999).

[4] N. Eustathopoulos: Curr. Opin. Solid. St. Mat. Sc. 9 (2005) 152.

[5] L. Yin, B. T. Murray, T. J. Singler: Acta Mater. 54 (2006) 3561.

[6] S. Avraham, W. D. Kaplan: J Mater. Sci. 40 (2005) 1093.

[7] W. J. Boettinger, C. A. Handwerker, U. R. Kattner, in: F. G. Yost, F. M. Hosking, D. R. Frear (Eds.) The Mechanics of Solder Alloy Wetting \& Spreading (1993) 103.

[8] F. G. Yost: Scripta Mater. 38 (1998) 1225.

[9] R. E. Loehman, A. P. Tomsia: J. Am. Ceram. Soc. 77 (1994) 271.

[10] A. Passerone, G. Valbusa, E. Biagini: J. Mater. Sci. 12 (1977) 2465.

[11] I. A. Aksay, C. E. Hoge, J. A. Pask: J. Phys. Chem. 78 (1974) 1178.

[12] Y. Naidich: Curr. Opin. Solid. St. Mat. Sc. 9 (2005) 161.

[13] N. Froumin, N. Frage, M. Polak, M. P. Dariel: Acta Mater. 48 (2000) 1435.

[14] S. H. Yang, S. Kang: J. Mater. Res. 15 (2000) 2238.

[15] E. A. Hayduk: Am. Ceram. Soc. Bull. 63 (1984) 1003.

[16] K. White, D. P. Kramer: Mater. Sci. Eng. 75 (1985) 207.

[17] J. C. Swearengen, R. J. Eagan: J. Mater. Sci. 11 (1976) 1857.

[18] S. Lopez-Esteban, E. Saiz, J. S. Moya, A. P. Tomsia: Langmuir 21 (2005) 2438.

[19] N. Sobczak, M. Singh, R. Asthana: Curr. Opin. Solid. St. Mat. Sc. 9 (2005) 241.

[20] L. Gremillard, E. Saiz, V. R. Radmilovic, A. P. Tomsia: J. Mater. Res. 21 (2006) 3222.

[21] E. Saiz, A. P. Tomsia: Nature Materials 3 (2004) 903.

[22] Y. V. Naidich, W. Sabuga, V. M. Perevertailo: Adgeziya Raspl. Pajka. Mater. 27 (1992)

23.

[23] E. Saiz, A. P. Tomsia, R. M. Cannon: Scripta Mater. 44 (2001) 159. 
[24] E. Saiz, A. P. Tomsia, R. M. Cannon: Acta Mater. 46 (1998) 2349.

[25] B. J. Keene: Int. Mat. Rev. 38 (1993) 157.

[26] T. Sugita, S. Ebisawa, K. Kawasaki: Surf. Sci. 20 (1970) 417.

[27] M. Nicholas, D. M. Poole: J. Mater. Sci. 2 (1967) 269.

[28] Y. Naidich, in: D. A. Candenhead, J. F. Danielli (Eds.) Progress in Surface, Membrane Science, Academic Press, New York (1981) 353.

[29] Outokumpu HSC Chemistry for Windows, (Outokumpu Research, Pori, Finland, 1993).

[30] B. C. Allen: J. Less-Com. Met. 29 (1972) 263.

[31] D. Chatain, E. Rabkin, J. Derenne, J. Bernardini: Acta Mater. 49 (2001) 1123.

[32] C. Serre, D. Chatain, P. Wynblatt, M. Muris, M. Bienfait: Metall. Mater. Trans. A 32 (2001) 2851.

[33] G. Levi, C. Scheu, W. D. Kaplan: Interface Sci. 9 (2001) 213.

[34] J. E. Lazaroff, P. D. Ownby, D. A. Weirauch, Jr.: J. Am. Ceram. Soc. 78 (1995) 539.

[35] W. Radigan, H. Ghiradella, H. L. Frisch, H. Schonhorn, T. K. Kwei: J. Colloid. Interf. Sci. 49 (1974) 241.

[36] E. Heikinheimo, A. Kodentsov, J. A. Vanbeek, J. T. Klomp, F. J. J. Vanloo: Acta Metall. Mater. 40 (1992) S111.

[37] L. M. Hocking, A. D. Rivers: J. Fluid Mech. 121 (1982) 425.

[38] E. Saiz, A. P. Tomsia, R. M. Cannon: in A. P. Tomsia, A. M. Glaeser (Eds.), Ceramic Microstructures. Control at the Atomic Level, Plenum Press, New York (1998) 65.

[39] N. Rauch, E. Saiz, A. P. Tomsia: Z. Metallkd. 94 (2003) 233.

[40] D. Chatain, F. Chabert, V. Ghetta, J. Fouletier: J. Am. Ceram. Soc. 76 (1993) 1568.

[41] D. Chatain, F. Chabert, V. Ghetta, J. Fouletier: J. Am. Ceram. Soc. 77 (1994) 197.

[42] J. G. Li: J. Am. Ceram. Soc. 75 (1992) 3118.

[43] V. K. Nagesh, A. P. Tomsia, J. A. Pask: J. Mater. Sci. 18 (1983) 2173.

[44] W. W. Mullins: J. Appl. Phys. 28 (1957) 333.

[45] E. G. Seebauer, C. E. Allen: Prog. Surf. Sci. 49 (1995) 265.

[46] D. A. Weirauch, D. P. Ziegler: J. Am. Ceram. Soc. 79 (1996) 920. 


\section{Corresponding Author:}

Antoni P. Tomsia

Materials Sciences Division

Lawrence Berkeley National Laboratory

MSD Building 62R0203

Berkeley, CA 94720, USA

Phone: 510-486-4918

Fax: $\quad 510-486-4761$

E-mail: aptomsia@lbl.gov 


\section{Table captions}

Table 1: Glass compositions (in wt. $\%$ ). Glass GTi has an addition of $3 \mathrm{~mol} . \% \mathrm{TiO}_{2}$ compared to the composition of glass G.

Table 2: Distribution (in \%) of Mo grains of different orientations on the polished Mo surface

Table 3: Expected vs. measured angles according to Eq. 1 with $\gamma_{\mathrm{lv}}^{\mathrm{Mo}}=2.1 \mathrm{~J} \mathrm{~m}^{-2}$ [25].

\section{Figure captions}

Fig. 1. Equilibrium contact angles for different metals on Mo. The black symbols correspond to experiments performed using the drop-transfer set-up under "non-equilibrated" conditions. The grey symbols correspond to "equilibrated" experiments.

Fig. 2. Optical micrographs of the triple junction between glass drops on Mo after cooling from experiments performed under reactive conditions. (a) Drop of GTi glass fired on Mo at $1200{ }^{\circ} \mathrm{C}$ for 4 hours $\left(p\left(\mathrm{O}_{2}\right) \approx 4 \cdot 10^{-23} \mathrm{~atm}\right)$. (b) Micrograph taken after removing the glass drop from an experiment performed using a glass without $\mathrm{TiO}_{2}(\mathrm{G})$ for 2 hours $\left(p\left(\mathrm{O}_{2}\right) \approx\right.$ $\left.4 \cdot 10^{-22} \mathrm{~atm}\right)$. In both cases the presence of discontinuous islands of reaction layer can be observed in the area close to the triple junction.

Fig. 3. AFM image of a triple-line ridge formed after spreading of a $\mathrm{G}$ glass (without $\mathrm{TiO}_{2}$ ) on Mo for 2 hours in an atmosphere with an oxygen partial pressure of $10^{-22}$ atm. The glass drop was dissolved to scan the area around the triple junction. The shape of the ridge corresponds to an evolution controlled by interfacial diffusion.

Fig. 4. Final contact angles for glasses with (GTi) and without (G) titania on Mo as a function of the oxygen partial pressure. The shaded area corresponds to the range of oxygen activities where chemical reactions between the glass and molybdenum are expected. 
Fig. 5. Calculated work of adhesion for the different liquids on Mo. The solid line represents $W_{\text {ad }}=2 \gamma_{\mathrm{lv}}$. Data for the same metals on $\mathrm{Al}_{2} \mathrm{O}_{3}$ (diamonds) is also presented for comparison [46].

Fig. 6. Time evolution of the groove widths on the Mo surface near a silver drop. The insert shows a typical grain boundary profile and its corresponding width $(w)$. Comparison with the contact angle data (Fig. 1) suggest that perhaps with only the exception of the experiments performed at $1070{ }^{\circ} \mathrm{C}$ for less than an hour, most of the groove growth occurs on "clean" surfaces free of oxygen.

Fig. 7. Temperature dependence of the surface diffusivity of molybdenum near a silver drop. 


\section{Table 1}

\begin{tabular}{|l|l|l|l|l|}
\hline & $\mathrm{SiO}_{2}$ & $\mathbf{C a O}$ & $\mathbf{A l}_{2} \mathbf{O}_{3}$ & $\mathbf{T i O}_{2}$ \\
\hline $\mathbf{G}$ & 62.00 & 23.00 & 15.00 & 0.00 \\
\hline $\mathbf{G T i}$ & 59.63 & 22.15 & 14.42 & 3.80 \\
\hline
\end{tabular}


Table 2

\begin{tabular}{|l|l|l|l|l|}
\hline Sample/Orientation & $(111)$ & $(100)$ & $(110)$ & $(311)$ \\
\hline Mo (after annealing for $1 \mathrm{~h}$ at $\left.1070^{\circ} \mathrm{C}\right)$ & 27.9 & 19.4 & 3 & 55.9 \\
\hline Mo (after annealing for $1 \mathrm{~h}$ at $\left.1070^{\circ} \mathrm{C}\right)$ & 18.1 & 22.8 & 2.4 & 53.7 \\
\hline
\end{tabular}


Table 3

\begin{tabular}{|l|l|l|l|l|l|l|}
\hline Metal & $T\left({ }^{\circ} \mathrm{C}\right)$ & $\gamma_{\mathrm{v}}\left(\mathrm{J} \mathrm{m}^{-2}\right)[21]$ & $\lambda\left(\mathrm{kJ} \mathrm{mol}^{-1}\right)$ & $L_{\mathrm{e}}^{\mathrm{Me}}\left(\mathrm{kJ} \mathrm{mol}^{-1}\right)$ & $\cos \theta_{0}($ calc $)$ & $\cos \theta_{0}(\exp )$ \\
\hline $\mathrm{Cu}$ & 1150 & 1.36 & 74.5 & 251.2 & 1.4 & 0.92 \\
\hline $\mathrm{Ag}$ & 1150 & 0.885 & 148 & 304.8 & 2.1 & 0.98 \\
\hline $\mathrm{Au}$ & 1100 & 1.138 & 13.5 & 342.4 & 1.8 & 0.91 \\
\hline $\mathrm{Sn}$ & 1190 & 0.467 & 83.5 & 296.4 & 4.3 & 0.98 \\
\hline
\end{tabular}




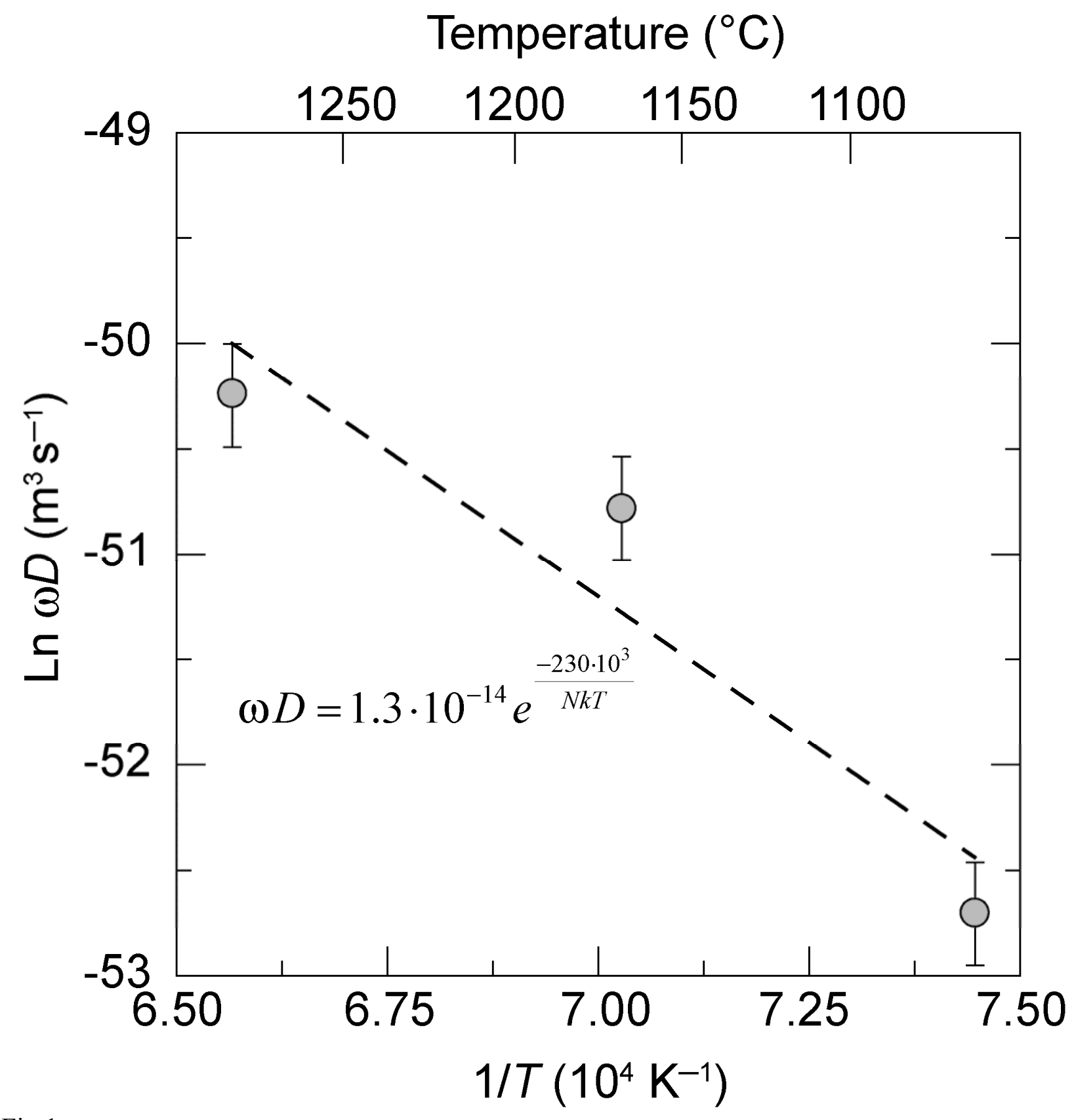

Fig 1 


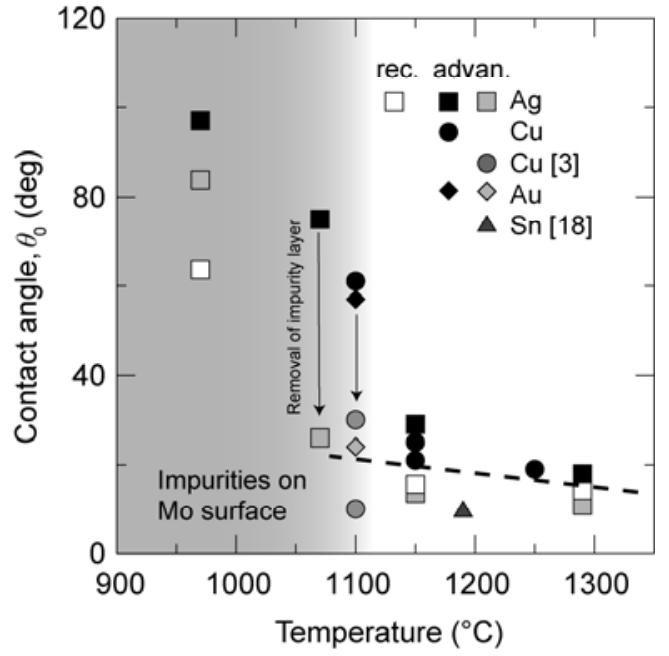

Fig 2 


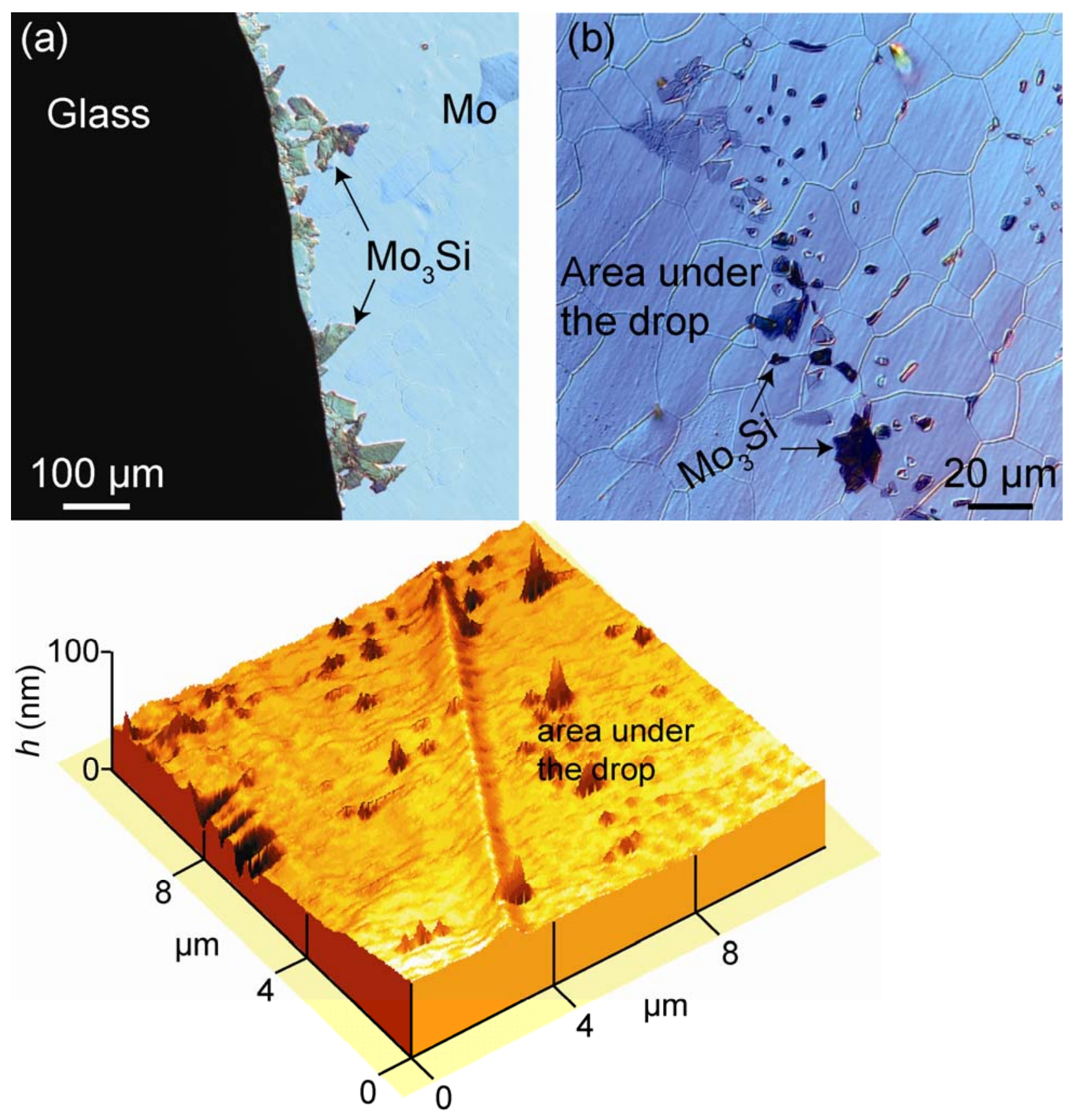

Fig 3 


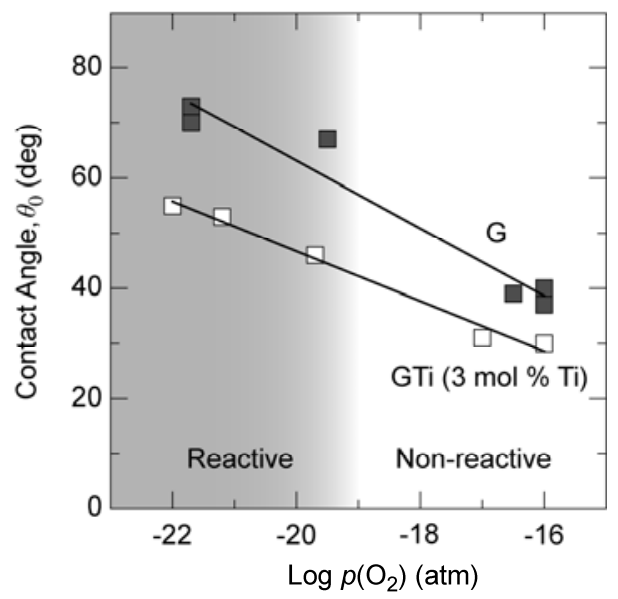

Fig4 


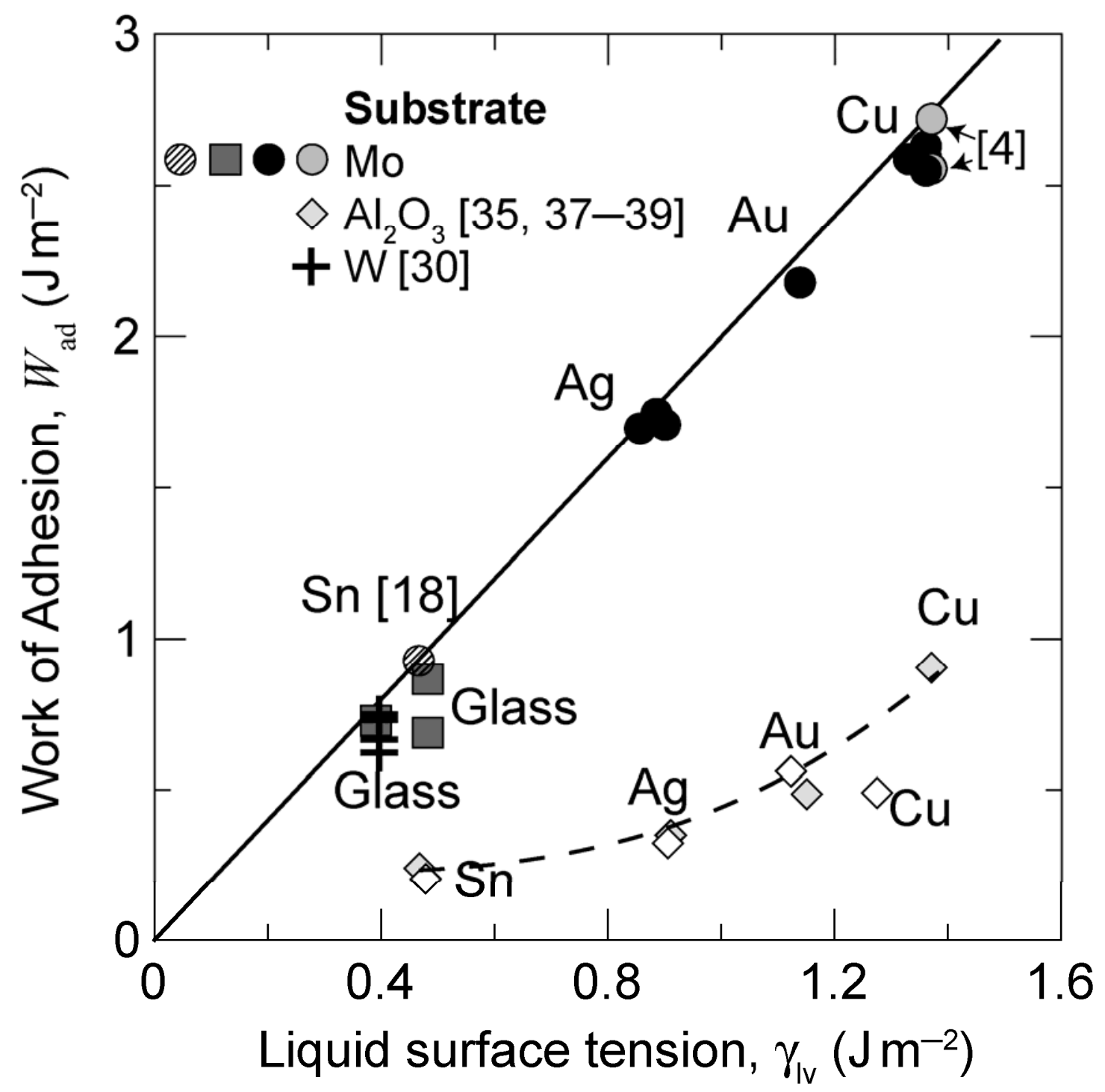

Fig 5 


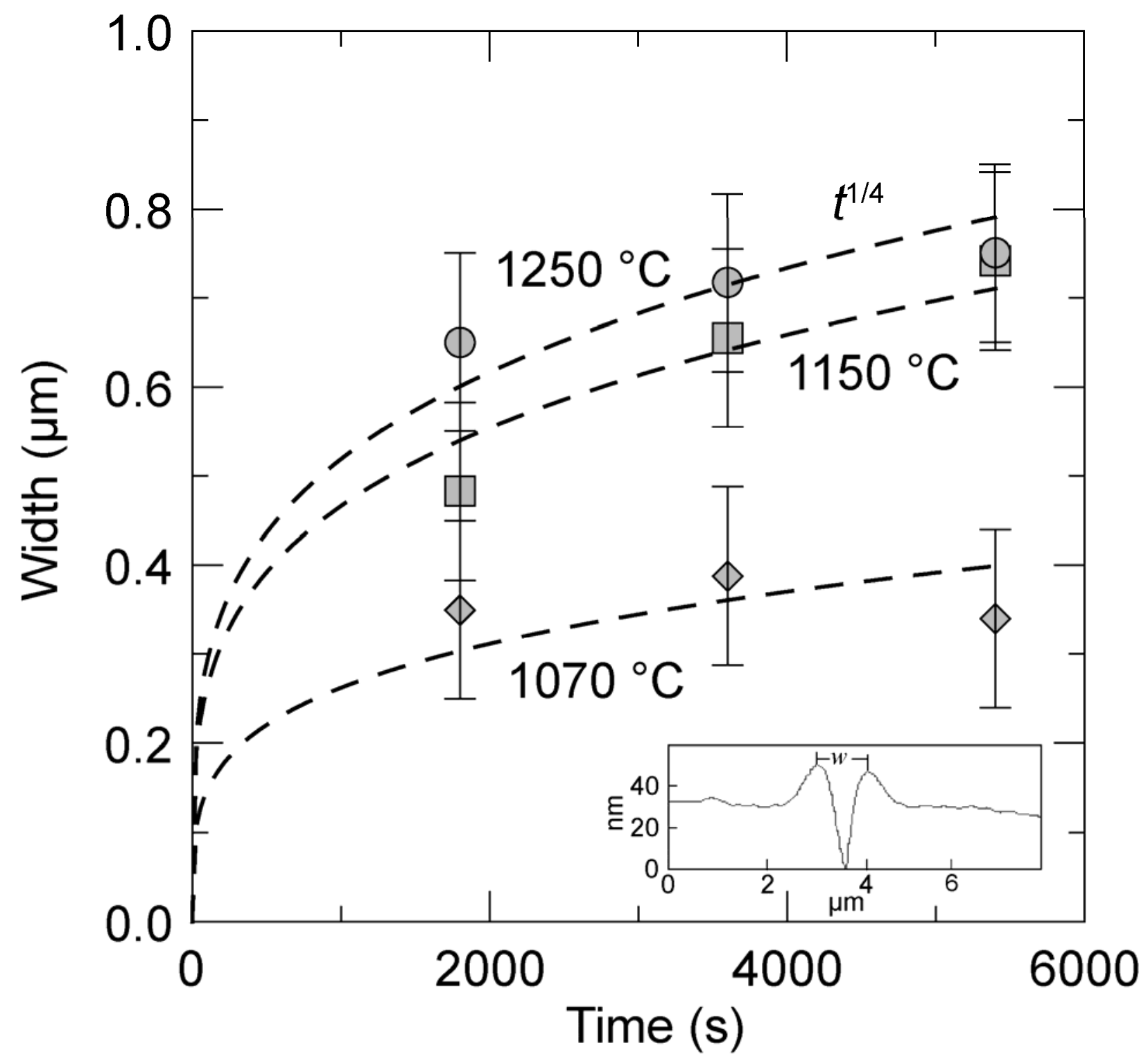

Fig 6 


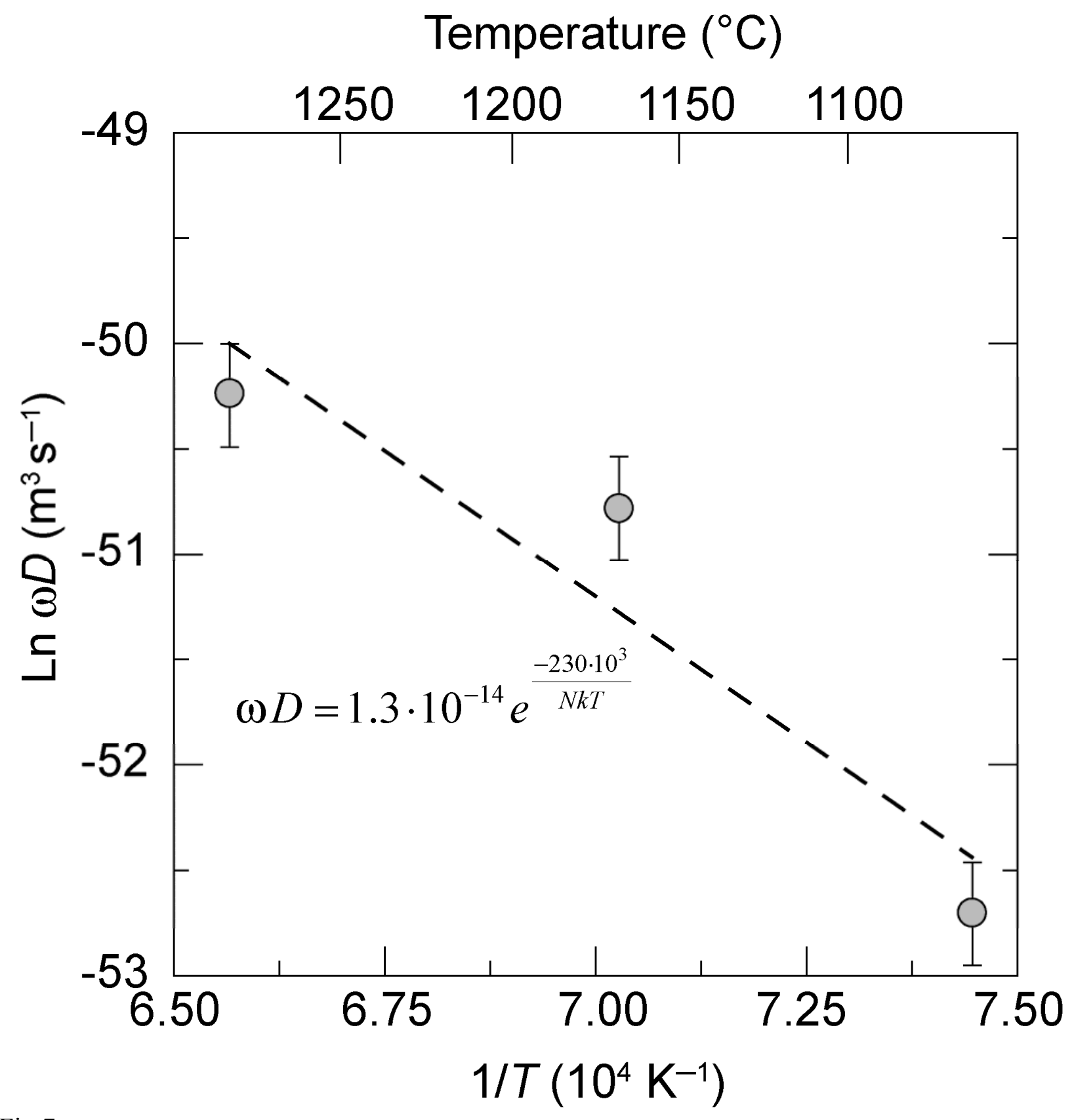

Fig 7 